A END Drom the Association

of Family Medicine

Residency Directors
Ann Fam Med 2014;12:584. doi: 10.1370/afm.1727.

\section{TRANSFORMING A TOOLBOX INTO A TREASURE CHEST}

When approaching a task there is nothing better than having a collection of useful tools organized in an easy-to-find location. This is especially true for family medicine residency program directors whose tasks seem endless, are often complex, and cover a myriad of issues.

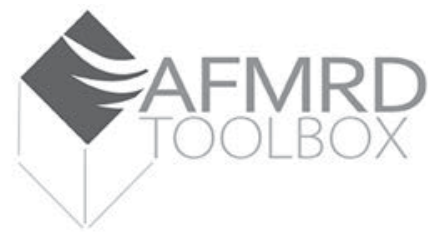

The mission of the Association of Family Medicine Residency Directors (AFMRD) is to inspire and empower family medicine residency program directors to achieve excellence in family medicine residency training. One way we aim to serve this mission is by providing our members with a great collection of tools.

On the AFMRD website (http://www.afmrd.org) is our AFMRD Toolbox, which over the years has grown to include various documents and processes as well as links to important websites. This toolbox has long been one of the AFMRD's most popular member benefits. Over time, however, some of these tools have become outdated or obsolete. As the number of tools piles up, finding the right tool becomes increasingly difficult. The good news is that a major initiative in the 2014-2016 AFMRD Strategic Plan is an overhaul of the toolbox.

Essentially, we are redesigning the old toolbox and creating a newly formatted "treasure chest" on the AFMRD website. Members of the AFMRD Toolbox Task Force are currently in the process of removing outdated tools and placing the remaining tools in a visually attractive space that will allow members to find what is needed easily.

Once the toolbox is built and existing content is organized, we will begin adding new tools, starting with a campaign asking all program directors to submit their best tools. The tools will be reviewed and, if accepted, placed in the toolbox for all to use. We are hopeful that by the 2015 Program Directors Workshop we will be able to demonstrate our new toolbox of treasures.

In addition to revamping and restocking our own toolbox, we assisted the Society of Teachers of Fam- ily Medicine (STFM) in collecting resources for the Residency Accreditation Toolkit. Dr. Ted Epperly led members of AFMRD and STFM as they worked collaboratively to develop this comprehensive collection of resources designed to help program directors with all aspects of implementing the Next Accreditation System and complying with milestones and the new RC-FM requirements. This toolkit is on the STFM website and available to AFMRD members at a discounted rate.

Though some items on background and implementation may seem basic to current program directors, they serve as an introduction to these concepts for new program directors, new faculty, and new staff. The Residency Accreditation Toolkit is divided into 6 broad categories: Milestones/Resident Assessment, Program Accreditation, Institutional Accreditation, Faculty Development, Coordinator Timeline, and General Accreditation Resources. Each section of the toolkit does an excellent job at providing a broad overview as well as drilling down into specifics. For example, in the Milestones section, Dr. Epperly provides a short video on why the ACGME created Milestones and their anticipated effect on graduate medical education. In addition, this section has multiple specific evaluation tools, with titles such as "cultural competency observation tool," "resident peer evaluation," and "observable behaviors list." For many of us, the Milestones have uncovered deficiencies in our assessment process. As we seek to plug those gaps, such tools will be invaluable.

In the future, the AFMRD hopes to add to its member resources a peer residency program innovation hub to evaluate and identify residency program innovations. There is no doubt that collectively we can create a powerful resource for all directors. Besides minimizing re-work and partnering with each other, the exciting potential of the use of shared resources is our collective ability to study our tools for validity and reliability. For example, we are lacking evidence that will help us produce better-trained family physicians. We also have little evidence that any of our assessment tools measure what we think they do. By using some of these assessment tools across residencies, there is the potential for educational research with sufficient power to determine what are "best practices."

This is truly an exciting time for AFMRD members seeking resources that will assist them in achieving excellence.

W. Fred Miser, MD and Stephen Schultz, MD Natasha Bbuyan, $M D_{i}$ Gretchen M. Dickson, MD, MBA, James W. Jarvis, $M D_{i}$ Lisa Maxwell, $M D_{i}$ Michael Mazzone, $M D_{i}$ Karen Mitchell, $M D_{i}$ Todd Shaffer, MD, MBA, Michael Tuggy, MD 